\title{
DEGRADAÇÃO FOTOCATALÍTICA DO CORANTE AZUL DE METILENO UTILIZANDO COMPOSTOS DE ZINCO
}

\author{
D. J. J. DE OLIVEIRA, R. G. MARQUES, R. BRACKMANN \\ Universidade Tecnológica Federal do Paraná, Departamento de Química \\ E-mail para contato: daimon.jung@ gmail.com \\ rubianegm@gmail.com \\ rodrigobrackmann@utfpr.edu.br
}

\begin{abstract}
RESUMO - Diversos estudos têm sido realizados para o desenvolvimento de formas mais eficientes de tratamento de efluentes industriais com o intuito de diminuir ou, até mesmo, eliminar sua toxicidade. Neste trabalho apresentado, foram realizadas fotocatálises do efluente fármaco azul de metileno em $\mathrm{pH}$ neutro, utilizando-se um reator tipo batelada resfriado por água, lâmpada de vapor de mercúrio $125 \mathrm{~W}$ UV e volume reacional de $150,0 \mathrm{~mL}$. Para verificar a porcentagem de degradação foi realizado análise de espectroscopia UV-VIS, na faixa de comprimento de onda de 400,0 a 800,0nm, utilizando-se $664 \mathrm{~nm}$ como o comprimento de onda da absorbância máxima. Foram observados altas taxas de degradação para todos os catalisadores utilizados, todas próximas dos $99 \%$ para o tempo de 30 minutos. Para realizar a caracterização dos catalisadores, foram realizadas análises de DRX na faixa de $2 \Theta=5-90^{\circ}$. Com essa análise, pode-se observar os sinais característicos da prata e, também, a altura do pico variando conforme a concentração de prata aumenta. Como o principal intuito é avaliar o processo fotocatalítico, escolheu-se a faixa de $\mathrm{pH}$ neutro, o qual ter-se-ia a menor influência da fotólise. Portanto, o objetivo principal da pesquisa é obter a eficiência do catalisador $(\mathrm{ZnO}$ e $\mathrm{ZnO} / \mathrm{Ag})$.
\end{abstract}

\section{INTRODUÇÃO}

Nos últimos anos, o crescimento do número de indústrias com alto potencial poluidor acarretou o consequente aumento da poluição de rios e afluentes. Devido a isso, métodos mais eficientes para o tratamento de resíduos danosos ao meio ambiente vêm sendo estudados mais veementemente com o intuito de reduzir ou, até mesmo, eliminar os contaminantes presentes nestes efluentes. Neste contexto, os Processos Oxidativos Avançados (POAs) são métodos que vêm sendo estudados para o tratamento de substâncias recalcitrantes presentes em diversos efluentes como compostos orgânicos que não são eliminados por meio de tratamento biológico ou outros métodos tradicionais.

Os POAs têm se mostrado muito eficientes devido a sua capacidade de degradar uma variedade de compostos recalcitrantes através de procedimentos de custo relativamente baixo e de simples operação ${ }^{1}$. Estes processos se baseiam na criação in situ do radical hidroxila (HO•), uma vez que estes compostos são altamente reativos e pouco seletivos, podendo atuar na oxidação química de uma vasta gama de substâncias ${ }^{2}$ resultando na mineralização dos 


\section{Congresso Brasileiro de Engenharia Química em Iniciação Científica UFSCar - São Carlos - SP 16 a 19 de Julho de 2017}

contaminantes a dióxido de carbono, água e íons inorgânicos ou, pelo menos, em produtos menos danosos ao meio ambiente ${ }^{3}$.

Entre os diversos tipos de POAs, a fotocatálise heterogênea tem recebido destaque. Esse processo baseia-se na geracão da hidroxila através da ativacão de um catalisador, um óxido semicondutor, pela absorção de fótons irradiados de uma fonte luminosa que pode ser artificial ou solar.

Os fotocatalisadores, sendo semicondutores, possuem uma descontinuidade de energia entre as bandas de conducão e de valência. Contudo, esses elétrons presentes na banda de valência podem superar essa barreira energética através da absorç̃o de energia, que deve maior ou igual à de bandgap, o que irá então promovê-los à banda de conducão, gerando um par elétron-lacuna ${ }^{4}$. Em meio aquoso, a formação do radical hidroxila ocorre na superfície do catalisador a partir de interações do par elétron-lacuna com as moléculas de água. ${ }^{5}$

Durante o processo fotocatalítico outro processo, denominado fotólise, pode ter lugar. Esta pode ocorrer por dois mecanismos principais: a fotólise direta, que é o processo onde a absorção de fótons promove excitação das moléculas do poluente, podendo dar início a reações fotoquímicas de degradação e, também, a fotólise indireta, a qual se tem a formação de intermediários reativos que podem sensibilizar a reação ${ }^{6}$.

Com o avanço das pesquisas na área de desenvolvimento de catalisadores, a modificação dos semicondutores por metais nobres tornou-se um campo importante onde a combinação do substrato semicondutor e grupamento de metais têm sido relatados devido ao melhoramento da atividade fotocatalítica através da captura dos portadores de carga fotoinduzidos ${ }^{7}$.

Neste sentido, o objetivo deste trabalho é a avaliação do efeito da deposição e da concentração de prata no metal semicondutor no processo fotocatalítico de degradação do fármaco azul de metileno.

\section{MATERIAIS E MÉTODOS}

Foram utilizadas lâmpadas UV de vapor de mercúrio de $125 \mathrm{~W}$ e um reator tipo batelada conforme mostra a Figura 1, recoberto por uma película refletora, de forma a garantir um maior aproveitamento da luz no interior do reator.

\section{Figura 1- Figura ilustrativa do fotoreator de bancada}

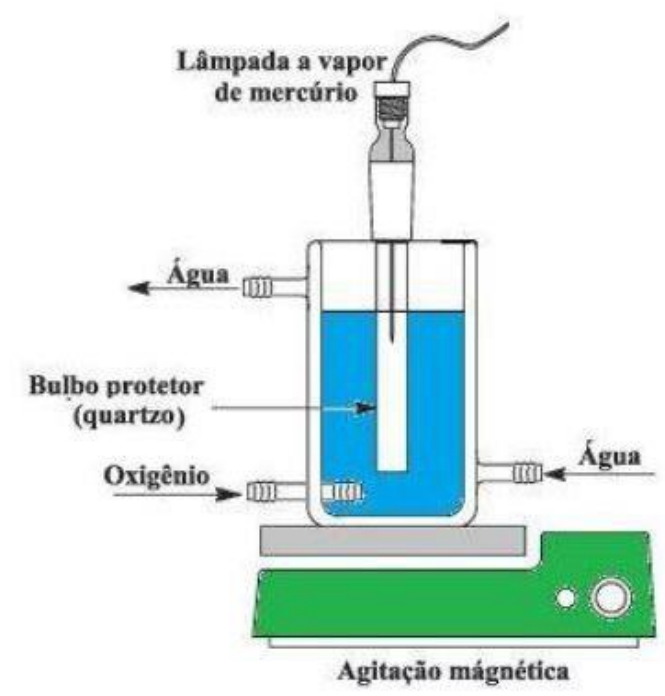


Preparo do efluente. Utilizando-se um balão volumétrico de 500,0mL foi preparada uma solução de azul de metileno de concentração $3,12 \times 10^{-5} \mathrm{~mol} \mathrm{~L}^{-1}$.

Preparo do catalisador. Para o preparo do óxido de zinco, comprado da empresa Biotec Produtos Químicos, uma pequena alíquota deste foi calcinado a $500{ }^{\circ} \mathrm{C}$ por $5 \mathrm{~h}$.

Deposição da prata. Uma dada quantidade de óxido de zinco e nitrato de prata foram solubilizados em água deionizada e colocados em rotaevaporador até a secagem, em temperatura de $80{ }^{\circ} \mathrm{C}$.

Processo fotolítico. Tempo de duração de $30 \mathrm{~min}$ e retirada de alíquotas de aproximadamente $5 \mathrm{~mL}$ a cada 5 min para análise em espectrômetro UV-VIS.

Processo fotocatalítico. Utilização de $1 \mathrm{~g}$ de catalisador por litro do efluente. Realização de adsorção, sob agitação, do catalisador por cerca de 5 min. Tempo de duração de 30 min e retirada de alíquotas de aproximadamente $5 \mathrm{~mL}$ a cada $5 \mathrm{~min}$ que, após a filtragem, foram conduzidas para análise de UV-VIS.

Varredura espectrômetro UV-VIS. As varreduras foram realizadas utilizando-se cubetas de quartzo em um intervalo de comprimento de onda de 400 a $800 \mathrm{~nm}$.

Difração de Raios-X. Foi utilizado um difratômetro MiniFlex 300/600 (40kV e 15mA), com velocidade de escaneamento de $1,00 \mathrm{~s}$ e largura do passo de $0,02^{\circ}$ por cerca de $1 \mathrm{~h}$. Intervalo de varredura de $2 \Theta=5-90^{\circ}$. O tamanho dos cristalitos foi calculado usando a equação de Scherrer:

$\mathrm{d}=(0,9 \lambda) /(\beta \cos (\Theta))$

Onde $\Theta$ é o ângulo de difração, $\beta$ represente a largura de meia altura do pico de difração e $\lambda$ é o comprimento de onda dos raios-X.

\section{RESULTADOS E DISCUSSÃO}

Teste fotocatalítico. O azul de metileno é um composto aromático heterocíclico, sólido à temperatura ambiente, solúvel em água e que produz uma solução de coloração azulada. Sua fórmula molecular é $\mathrm{C}_{16} \mathrm{H}_{18} \mathrm{ClN}_{3} \mathrm{~S}$ e sua massa molecular $319,85 \mathrm{~g} \mathrm{~mol}^{-1}$. Apresenta maior absorbância no comprimento de onda de $664 \mathrm{~nm}$, que foi utilizado para analisar a degradação do corante.

Para estudar a degradação do azul de metileno, foram utilizados catalisadores de óxido de zinco, com e sem deposição de prata.

Observando-se a Figura 2, que apresenta a degradação do composto em função do tempo, através da absorbância, verifica-se que ao final do processo fotocatalítico foram obtidos resultados muito semelhantes de degradação do corante para todos os catalisadores. No entanto, como pode-se observar, o catalisador $\mathrm{ZnO}-\mathrm{Ag}$ 1,0\% é capaz de degradar em torno de $99 \%$ do corante logo no início da reação, que é seguida de uma significativa queda na porcentagem de degradação. Essa significativa diminuição da absorbância pode ter relação com a formação de intermediários que absorvem a luz na mesma região do espectro. 
Figura 2- Porcentagem de degradação do corante utilizando-se diferentes catalisadores

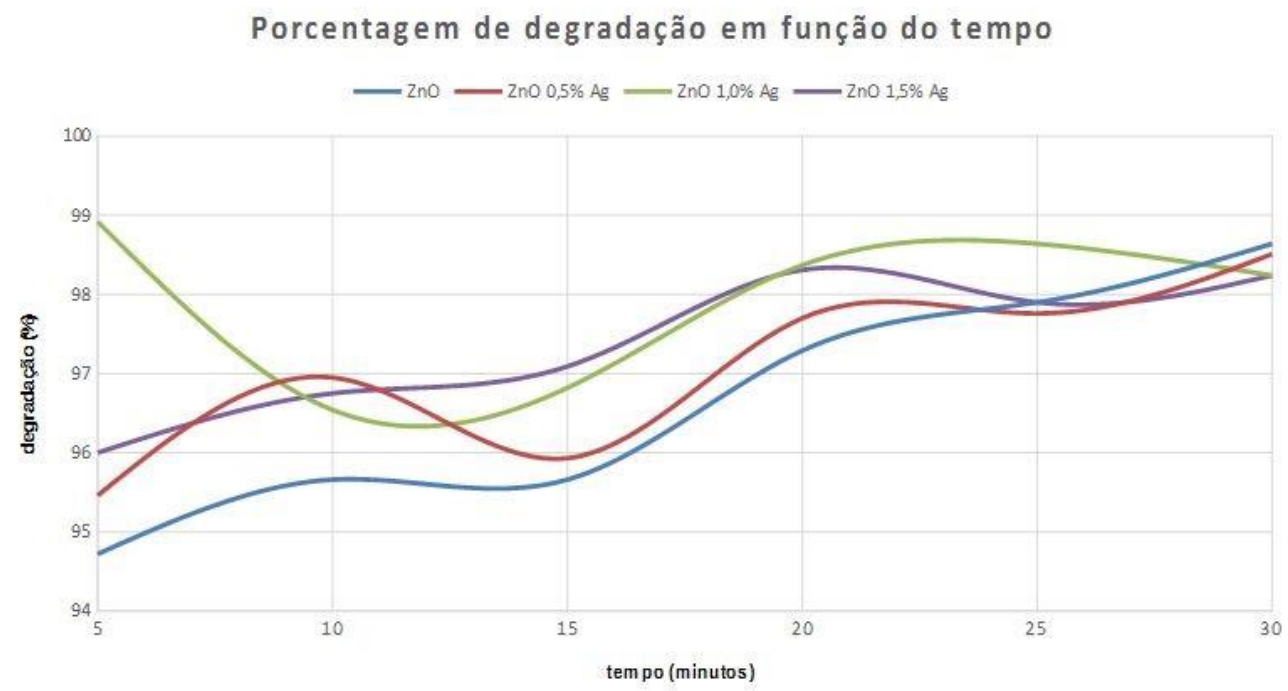

Caracterização por DRX. O padrão de DRX dos catalisadores evidenciou que a deposição de prata não alterou a estrutura do óxido de zinco, afirmada por Zheng et al (2007), "o fato de não haver mudança nos picos de difração, implica que nenhuma solução sólida de $\mathrm{Zn}_{1-\mathrm{x}} \mathrm{Ag}_{\mathrm{x}} \mathrm{O}$ é formada e a mudança nos parâmetros de rede dos nanocristais de $\mathrm{ZnO}$ deve ser desprezível". As amostras se mostraram altamente cristalinas. Com a deposição de prata na superfície do óxido de zinco, ocorre o melhoramento de uma propriedade que, segundo Zhang et al (2012), diz que "as ilhas de metal depositadas na superfície do semicondutor têm sido mostradas por capturar eficazmente os elétrons promovidos para a banda de condução e assim os orifícios livres formados na banda de valência podem participar em reações de oxidação".

Figura 3- DRX dos padrões do óxido de zinco variando a concentração de prata impregnada

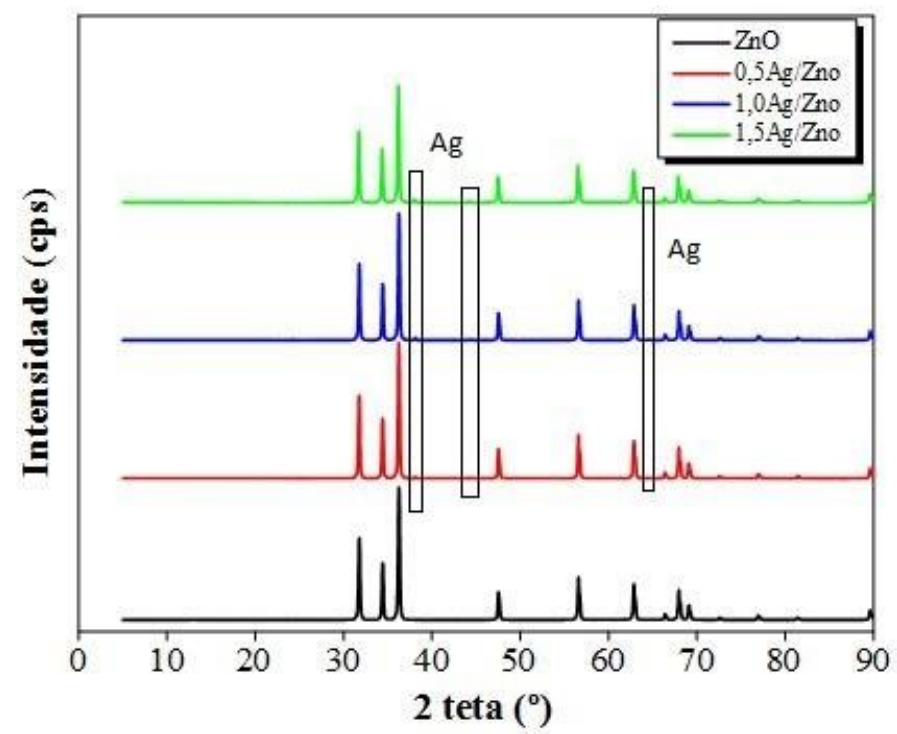




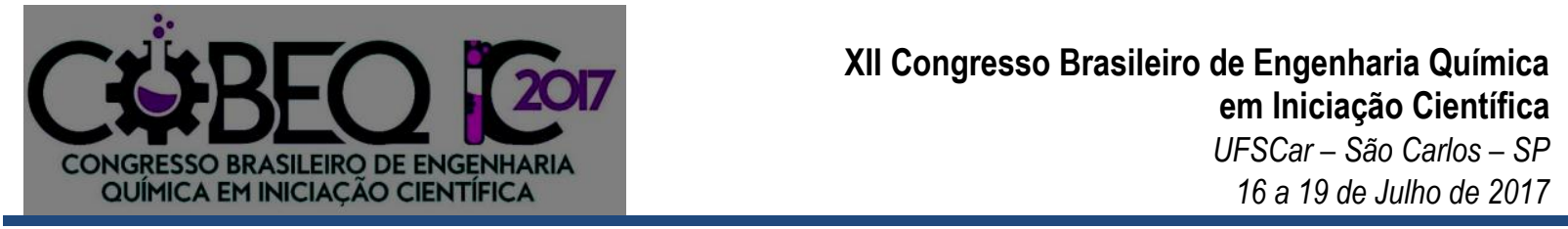

Observando a Figura 4 a seguir, pode-se concluir de que o aumento da concentração de prata presente no catalisador teve uma pequena influencia no tamanho do cristalito, sendo esse tamanho influenciado principalmente pelo método de preparo do óxido.

Figura 4. Tamanho do cristalito calculado pela equação de Scherrer

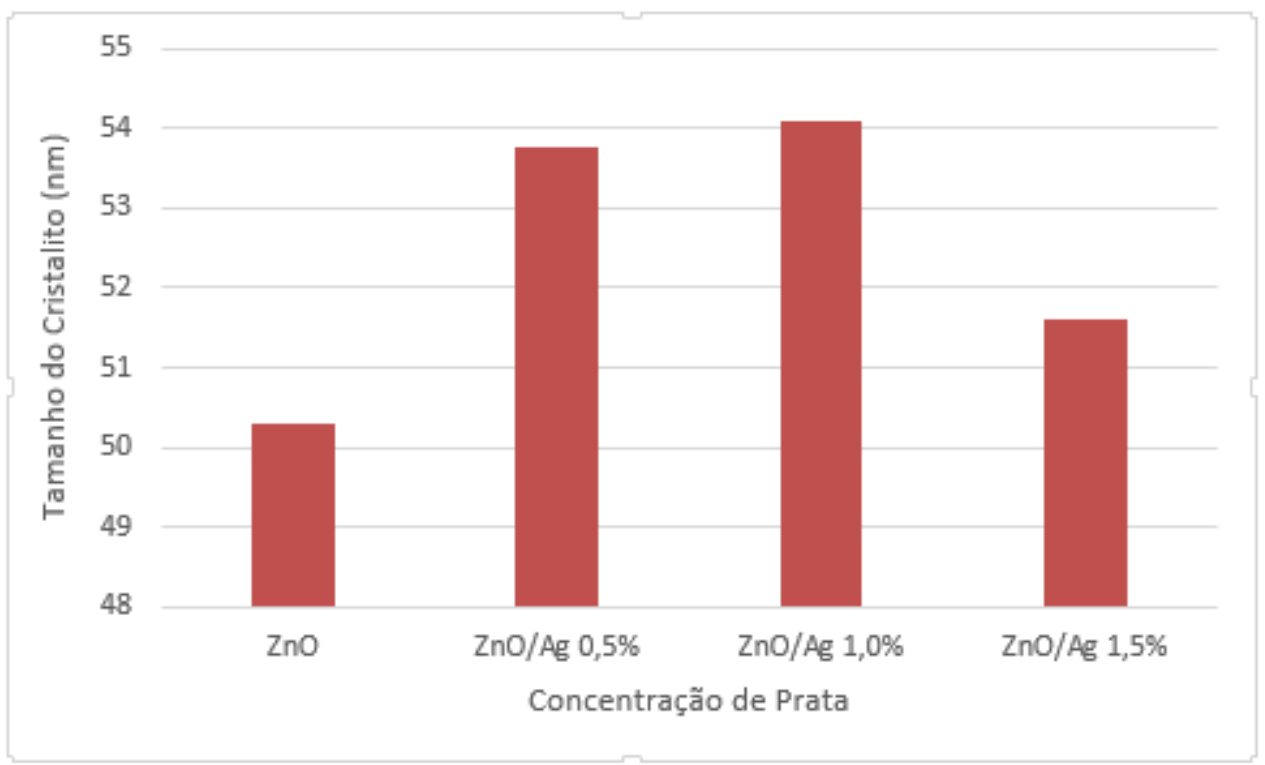

\section{CONCLUSÃO}

Os diversos tipos de resíduos de corantes provocam um grande impacto ambiental e necessitam algum tratamento para minimizar os danos ambientais. Para isso, os experimentos realizados com o corante azul de metileno se mostraram eficientes, obtendo uma degradação maior que $98 \%$, tanto com a utilização de $\mathrm{ZnO}$ quanto $\mathrm{ZnO}-\mathrm{Ag}$ x\%. Porém, nos experimentos realizados a prata não demonstrou uma significativa melhora na degradação do azul de metileno. Essa baixa diferença com o uso da prata pode ter relação com o tamanho do cristalito levemente elevado que, segundo Dodd et al (2006. apud GEORGEKUTTY, 2008) reportam "que existe um tamanho ótimo que levaria a uma máxima atividade fotocatalítica”.

\section{REFERÊNCIAS}

${ }^{3}$ ANDREOZZI, R.; CAPRIO, V.; INSOLA, A.; MAROTTA, R. Advanced oxidation processes (AOP) for water purification and recovery. Catalysis Today, v. 53, n. 1, p. 51-59, 1999.

GEORGEKUTTY, R.; SEERY, M. K.; PILLAI, S. C. A highly efficient Ag-ZnO photocatalyst: Synthesis, properties, and mechanism. Journal of Physical Chemistry C, v. 112, n. 35, p. 13563-13570, 2008.

${ }^{4,7}$ HEIGHT, M. J.; PRATSINIS, S. E.; MEKASUWANDUMRONG, O. Ag-ZnO catalysts for UV-photodegradation of methylene blue. Applied Catalysis B: Environmental, v. 63, n. 3-4, p. 305-312, 2006. 
${ }^{6}$ LEE, E.; GLOVER, C. M., ROSARIO-ORTIZ, F. O., Photochemical Formation of Hydroxyl Radical from Effluent Organic Matter: Role of Composition. Environm. Sci. \& Tech., v. 47, p. 12073-12080, 2013.

${ }^{2}$ MELO, S. A. S.; TROVÓ, A. G.; BAUTITZ, I. R.; NOGUEIRA, R. F. P. Degradação de fármacos residuais por processos oxidativos avançados. Quimica Nova, v. 32, n. 1, p. 188-197, 2009.

${ }^{1,5}$ VIANNA, V. B.; TÔRRES, A. R.; AZEVEDO, E. B. Degradação de corantes ácidos por processos oxidativos avançados usando um reator com disco rotatório de baixa velocidade. Química Nova, v. 31, n. 6, p. 1353-1358, 2008.

ZHANG, D. Effects of deposited metallic silver on nano-ZnO for the environmental purification of dye pollutants. South African Journal of Chemistry, v. 65, p. 98-103, 2012

ZHENG, Y.; ZHENG, L; ZHAN, Y.; LIN, X.; ZHENG, Q.; WEI, K. Ag/ZnO heterostructure nanocrystals: Synthesis, characterization, and photocatalysis. Inorganic Chemistry, v. 46, n. 17, p. 6980-6986, 2007. 